\title{
Écocitoyenneté : des idées aux actes favorables à
} l'environnement

Colloque des 17 et 18 novembre 2008 Marseille, France

\section{Alain Legardez}

\section{(2) OpenEdition}

\section{Journals}

Édition électronique

URL : http://journals.openedition.org/ere/2273

DOI : $10.4000 /$ ere.2273

ISSN : 2561-2271

Éditeur

Centr'ERE

Référence électronique

Alain Legardez, «Écocitoyenneté : des idées aux actes favorables à l'environnement », Éducation

relative à l'environnement [En ligne], Volume 8 | 2009, mis en ligne le 20 décembre 2009, consulté le 21 février 2020. URL : http://journals.openedition.org/ere/2273 ; DOI : 10.4000/ere.2273 


\section{Écocitoyenneté : des idées aux actes favorables à l'environnement}

Colloque des 17 et 18 novembre 2008 Marseille, France

\section{Alain Legardez}

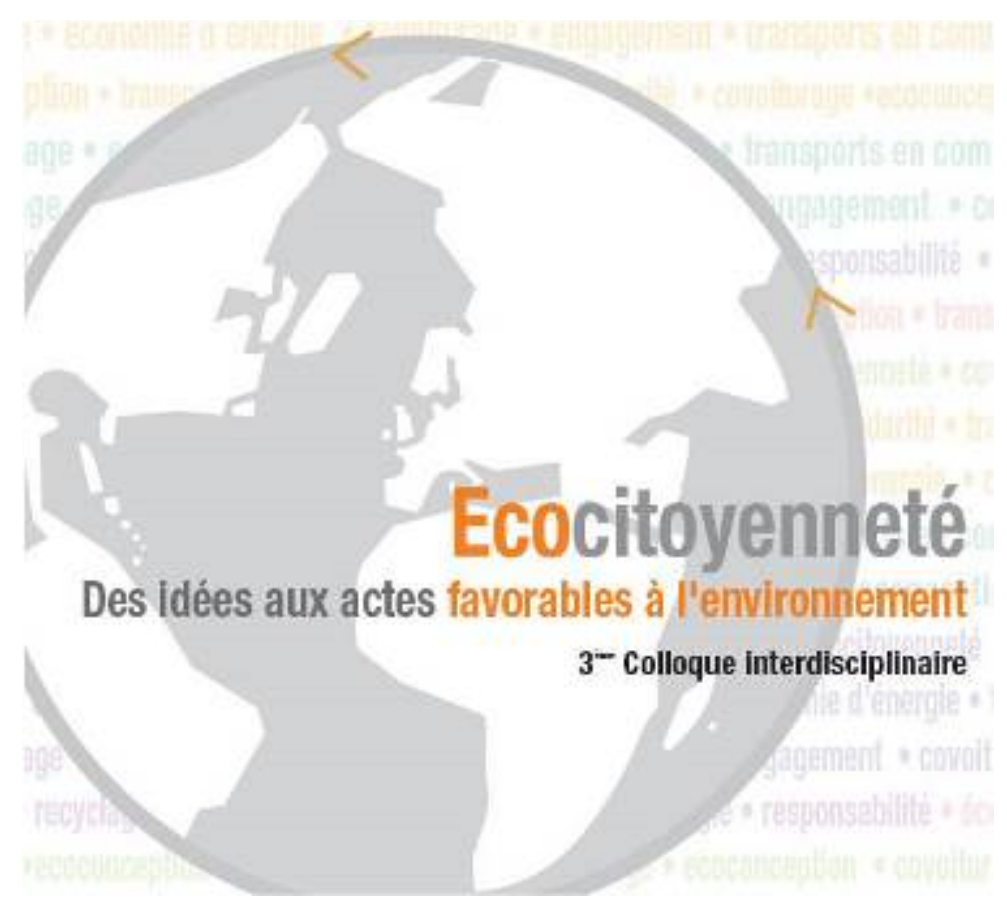

1 Le 3ème colloque interdisciplinaire sur l'écocitoyenneté s'est tenu à Marseille les 17 et 18 novembre 2008, sous l'égide du Conseil Régional Province- Alpes-Côte d'Azur (PACA), de l'Agence de l'Environnement et de la Maîtrise de l'Énergie (ADEME)-PACA et de l'Université de Provence. Il marquait essentiellement la fin de travaux menés en partenariat entre des associations et des équipes de chercheurs universitaires sur le thème « Recherche - Action - Écocitoyenneté », suite à un appel d'offre de la région et de l'ADEME. 
2 La première journée a d'abord été consacrée à la présentation du dispositif innovant de « recherche-action » suscité par l'appel d'offre (par Michel Graillat de l'ADEME), suivie des principaux résultats d'une recherche menée sur ce «dispositif de recherche participative et coopérative » (par Françoise Bernard de l'Université de Provence), puis d'une réflexion stimulante sur « écocitoyenneté et démocratie » (par Éric Dacheux de l'Université de Clermont-Ferrand).

3 L'après-midi a été consacrée entièrement à la présentation et la discussion des sept recherches qui ont duré deux années, regroupées en trois ateliers.

4 Ces présentations et ces discussions ont suscité un grand intérêt auprès de participants issus de milieux très divers : chercheurs, étudiants, associatifs liés à l'environnement, décideurs locaux, militants, etc. Des preuves ont été données que des résultats encourageants pour la promotion de comportements favorables à l'environnement peuvent être obtenus dans un cadre associatif, en utilisant des dispositifs qui s'appuient sur des recherches universitaires menées par des équipes reconnues. Les travaux de référence concernent particulièrement la psychologie sociale du comportement, la coconstruction des savoirs et des identités. Les outils testés dans le cadre associatif vont $\mathrm{du}$ « théâtre forum » aux « actions engageantes », de questionnaires de représentations à des débats écocitoyens entre pairs et avec experts. Chacun a pu apprécier les résultats de ces démarches innovantes, même si la pérennité des résultats ne peut encore être avérée. Par contre, la pérennisation des dispositifs semble prouvée, alors même que les équipes de recherche s'en sont désormais retirées.

5 La seconde journée a été consacrée à une série de communications sélectionnées par le conseil scientifique du colloque et émanant de chercheurs français et étrangers.

6 Le colloque s'est achevé par une intervention d'un "grand témoin " (Piero Amerio de l'Université de Turin) et par des conclusions et perspectives esquissées par les organisateurs institutionnels. En particulier, une suite est envisagée qui concernerait un dispositif qui associerait équipes de recherches, associations et collectivités locales. Le 4ème colloque sur l'écocitoyenneté est envisagé à la fin de ce nouveau cycle de « recherches - actions - écocitoyenneté ».

7 Voir les actes du $1^{\text {er }}$ colloque sur l'écocitoyenneté : http://environnement. 34500.free.fr/docs/ActesEcocit2.pdf

\section{AUTEUR}

\section{ALAIN LEGARDEZ}

Université de Provence et UMR ADEF 